\title{
PACIENTŲ LYTIES, AMŽIAUS BEI NAUDOJAMO OPERACINIO PJŪVIO İTAKA REVIZIJŲ DAŽNIUI PO KELIO SĄNARIO ENDOPROTEZAVIMO OPERACIJOS
}

\author{
Algimantas Čebatorius ${ }^{1,4}$, Aleksej Lebedev ${ }^{1}$, Justinas Stučinskas ${ }^{2}$, Simonas Laukaitis ${ }^{2}$, \\ Donatas Senkanec ${ }^{3}$ \\ ${ }^{1}$ Klaipèdos universitetine ligonine, Traumatologijos skyrius, \\ ${ }^{2}$ Lietuvos sveikatos mokslu universiteto Kauno klinikos, Ortropedijos-traumatologijos klinika, \\ ${ }^{3}$ Kauno klinikiné ligoninè, Traumatologijos skyrius, \\ ${ }^{4}$ Klaipedos universiteto Reabilitacijos katedra
}

Raktažodžiai: kelio sąnario endoprotezavimas, osteoartrozè, operacinis pjūvis, revizinè operacija, Lietuovs sąnarių endoprotezavimo registras, implantų išlikimas.

\begin{abstract}
Santrauka
Kelio sąnario keitimo procedūra yra viena iš dažniausiai atliekamų ortopedinių operacijų Lietuvoje. Daugybė veiksnių turi ịtakos gydymo rezultatams. Šios studijos tikslas buvo ịvertinti paciento lyties, amžiaus bei naudojamo operacinio pjūvio įtaką pakartotinių operacijų dažniui pacientams, kuriems atliekamos kelio sąnario endoprotezavimo operacijos. I tyrimą buvo ịtraukti visi LSER duomenų bazèje užregistruoti pirminiai kelio sąnario endoprotezavimo atvejai nuo $2011 \mathrm{~m}$. sausio $1 \mathrm{~d}$. iki $2013 \mathrm{~m}$. gruodžio 31 d. ir stebèti iki 2014 m. gruodžio 31 dienos. Taip pat registruotos pakartotinès endoprotezavimo operacijos (revizijos). Pagrindiniu vertinimo kriterijumi buvo implantų išlikimo dažnis po pirminès operacijos. Tyrimo duomenimis, per 2011-2013 metus kelio sąnario keitimo operacija atlikta 4436 moterims ir 1119 vyrams. Didžioji dalis kelio sąnario endoprotezavimo operacijų (88 proc.) atlikta klasikiniu medialiniu parapateliariniu pjūviu. Sekimo laikotarpiu registruotos 59 revizinès operacijos. Tai sudaro 1,1 proc. Kelio sąnario implantų išlikimas siekè 98,9 proc. praejjus vidutiniškai 30 mènesių po pirminès operacijos. Stebèti šiek tiek geresni vyriškosios lyties pacientų implantų išlikimo rezultatai (99,0 proc.) nei moteriškosios ( 98,9 proc.), tačiau skirtumas nèra statistiškai reikšmingas. Palyginus kelio sąnario implantų išlikimą tarp dviejų amžiaus grupių, t.y. per 60 metų ir iki 60 metų, stebėta,
\end{abstract}

kad pacientų iki 60 metų amžiaus grupeje EP išlikimo rezultatai yra blogesni $(98,4$ proc.) per 60 metu (99,1 proc.)

\section{İvadas}

Sąnarių endoprotezavimo operacijos neretai yra priskiriamos vieniems iš didžiausių šių dienų medicinos pasiekimų. Tai neabejotinai yra vienos efektyviausių pastaruoju metu atliekamų chirurginių intervencijų tiek medicinine, tiek ekonomine prasme $(1,2)$. Kelio sąnario keitimo procedūra yra viena iš dažniausiai atliekamų ortopedinių operacijų Lietuvoje - šių operacijų pastaruoju laikotarpiu atliekama apie 2000 kasmet (3). Dažniausi veiksniai, turintys itakos gydymo rezultatams, yra paciento amžius, lytis, diagnozè, implanto tipas, pjūvis, taikoma operacinè technika bei daugelis kitų $(4,5)$.

Siekiant ịvertinti operacinio gydymo rezultatus, daugumoje Europos Sajungos šalių veikia nacionaliniai endoprotezavimo registrai(6). Sistemingai surinkti duomenys leidžia ịvertinti operacijų rezultatus, implantų bei operacinès technikos kokybę ir suteikia galimybę analizuoti pakartotinai atliekamų operacijų priežastis (7).

Lietuvoje iki 2011 metų atliktų sąnarių endoprotezavimo operacijų duomenys, kurie turètų reikšmès klinikiniam darbui, renkami nebuvo. 2011 metais įkurtas Lietuvos sąnarių endoprotezavimo registras (LSER) (3). Nuo to laiko pradèti rinkti duomenys apie visose Lietuvos gydymo įstaigose atliktas kelio ir klubo sąnarių endoprotezavimo operacijas.

Darbo tikslas: ivvertinti paciento lyties, amžiaus bei naudojamo operacinio pjūvio įtaką pakartotinų operacijų dažniui pacientams, kuriems atliekamos kelio sąnario endoprotezavimo operacijos. 


\section{Darbo objektas ir metodika}

I tyrimą buvo ịtraukti visi LSER duomenų bazèje užregistruoti pirminiai kelio sąnarių endoprotezavimo atvejai nuo $2011 \mathrm{~m}$. sausio 1 d. iki $2013 \mathrm{~m}$. gruodžio $31 \mathrm{~d}$. Itraukti pacientai stebèti iki $2014 \mathrm{~m}$. gruodžio 31 dienos. Tyrime dalyvavo 24 Lietuvos gydymo įstaigos, kuriose atliekamos šios operacijos. Visų tyrime dalyvaujančių ligoninių gydytojai ortopedai traumatologai po atliktos operacijos pilde elektroninę operacijos duomenų registracijos formą $(8,9)$. Kiekvienos ligoninès gydytojai prisijungti prie šios duomenų bazès bei užpildyti elektroninę operacijos registracijos formą galèjo naudodamiesi ịstaigai suteiktu vartotojo vardu ir slaptažodžiu. Gydytojų ir gydymo įstaigų dalyvavimas buvo neprivalomas, t.y. pagrịstas savanoriškumo/geranoriškumo principu. Pacientų identifikavimui naudotas

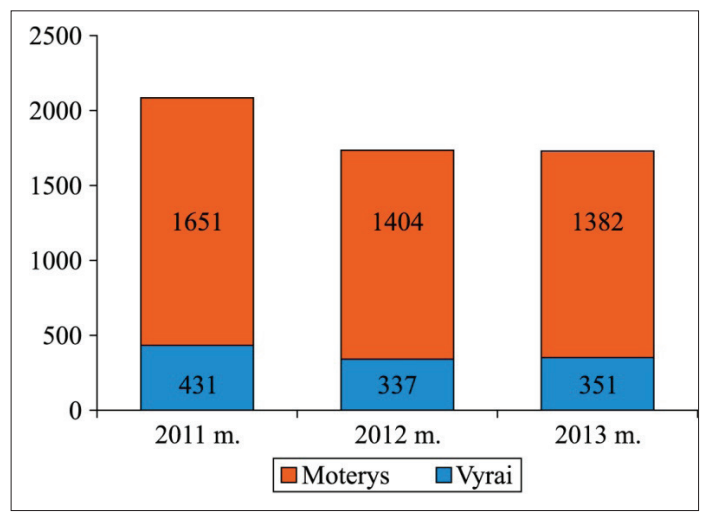

1 pav. Pacientų, kuriems atlikta kelio sąnario EP operacija, pasiskirstymas pagal lytị

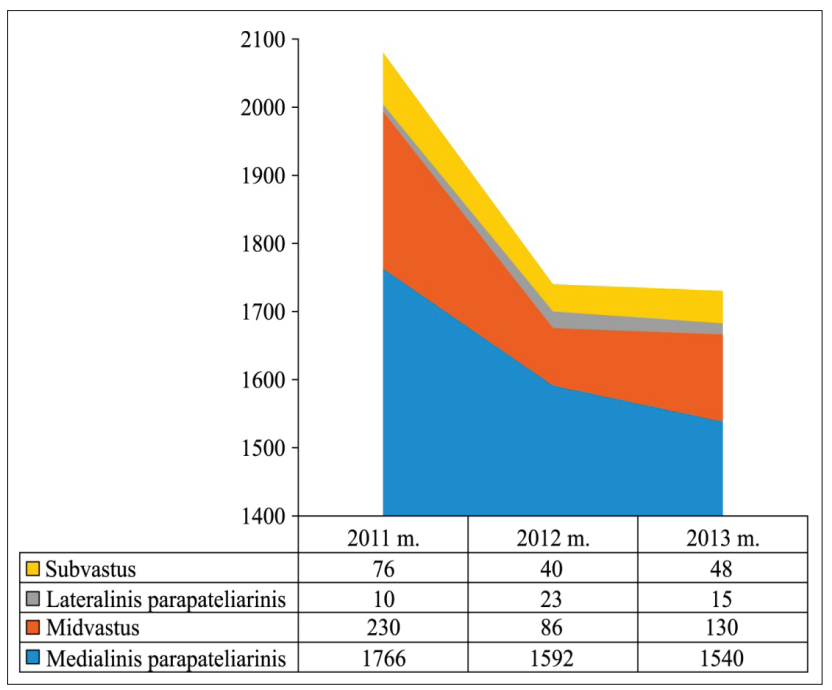

2 pav. Kelio sąnario endoprotezavimui naudotų operacinių pjūvių pasiskirstymas unikalus identifikacijos numeris (asmens kodas). Asmens kodo naudojimas vèliau leido nesunkiai nustatyti, kuriems pacientams atliktos pakartotinès operacijos(10).

Registruoti daugybiniai veiksniai, turintys itakos pacientų operacinio gydymo rezultatams, tarp kurių buvo ir pacientų demografiniai duomenys, bei taikomas operacinis pjūvis.

Taip pat registruotos pakartotinès endoprotezavimo operacijos(revizijos) bei jų data. Revizija apibrèžta kaip pakartotine to paties sąnario operacija, kurios metu buvo pakeistas, pridètas arba pašalintas bent vienas iš EP komponentų.

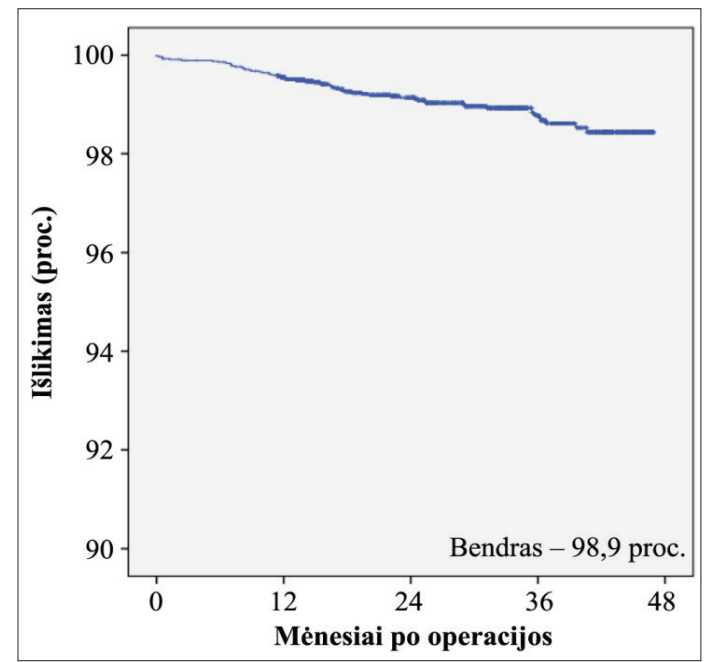

3 pav. Kaplan-Meier kelio sąnario EP išlikimo kreivė

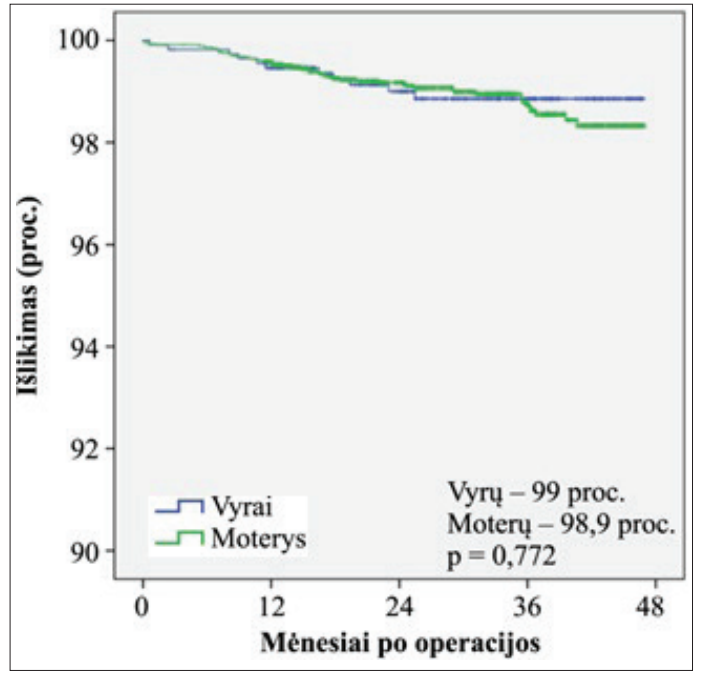

4 pav. Vyrų ir moterų kelio sąnario EP rezultatų palyginimas 
Pagrindiniu vertinimo kriterijumi buvo implantų išlikimo dažnis po pirminès kelio sąnario endoprotezavimo operacijos. Pacientų sekimo periodas prasidèdavo po atliktos operacijos ir tęsdavosi iki paciento mirties arba stebejjimo periodo pabaigos (2014 metų gruodžio 31 diena). Pacientai, kurie iki minèto periodo nebuvo dar kartą operuoti, buvo laikomi sėkmingais atvejais, t. y. su funkcionuojančiais endoprotezuotais sąnariais. O tie pacientai, kuriems buvo atliktos protezuoto sąnario pakartotinès operacijos, buvo laikomi nesèkmingais atvejais, revizijos datą laikant stebèjimo periodo pabaiga.

Sąnarių endoprotezavimo operacijų duomenų aprašomajai statistikai naudoti vidurkiai, medianos bei pasikliautiniai intervalai (PI). EP išlikimo kreivèms įvertinti naudotas Kaplan-Meier metodas. Išlikimo kreivių palyginimui buvo taikytas Log-rank testas. Skirtumas buvo laikomas statistiškai reikšmingu, kai $\mathrm{p}<0,05$. Duomenų analizè buvo atlikta naudojantis SPSS ir STATA programiniu paketu.

Šiam moksliniam tyrimui išduotas bioetikos leidimas $\mathrm{Nr}$. BE-2-17.

\section{Rezultatai}

Tyrimo duomenimis, per 2011-2013 metus kelio sąnario keitimo operacija atlikta 4436 moterims, kurių amžiaus vidurkis buvo $69 \pm 9$ metai, ir 1119 vyrams, kurių amžiaus vidurkis buvo $67 \pm 10$ metų. Pacientų pasiskirstymas pagal lytị kiekvienais metais pateiktas 1 pav. Kelio sąnario endoprotezavimo operacijos atliktos naudojant medialini parapateliarini, midvastus, subvastus arba lateralini parapateliarini pjūvius. Kaip ir visame pasaulyje(11), didžioji dalis kelio sąnario endoprotezavimo operacijų (88 proc.) atlik-

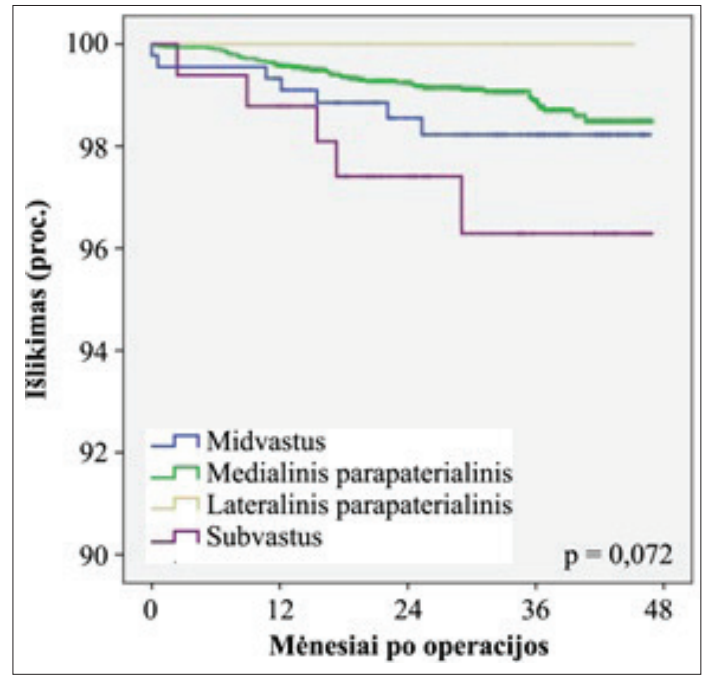

5 pav. Operacinių pjūvių išlikimo rezultatų palyginimai ta klasikiniu medialiniu parapateliariniu pjūviu (2 pav.).

Iki 20141231 pacientams, kuriems pirminès kelio sąnario keitimo operacijos atliktos 2011-2013 metais, buvo registruotos 59 revizinès operacijos. Tai sudaro 1,1 proc. nuo 2011-2013 metais atliktų pirminių kelio sąnario endoprotezavimo operacijų. Bendras kelio sąnario implantų išlikimas siekė 98,9 proc. praejjus vidutiniškai 30 mėnesių po pirminès operacijos ( 3 pav.).

EP išlikimo rezultatai buvo lyginami atsižvelgiant ị paciento lytị. Kaip matyti 4 pav., šiek tiek geresni vyriškosios lyties pacientų implantų išlikimo rezultatai ( 99,0 proc.) nei moteriškosios ( 98,9 proc.), tačiau nustatytas skirtumas nèra statistiškai reikšmingas $(\mathrm{p}=0,772)$. Vertinant operacinių pjūvių įtaką išlikimo rezultatams, stebimas mažesnis kelio sąnario EP išlikimas naudojant subvastus pjūvị, lyginant su kitais kelio sąnario operaciniais pjūviais, nors skirtumas taip pat nèra statistiškai reikšmingas $(\mathrm{p}=0,072)(5$ pav.).

Palyginus kelio sąnario implantų išlikimą tarp dviejų amžiaus grupių, t.y. per 60 metų ir iki 60 metų, stebèta, kad pacientų iki 60 metų amžiaus grupejje EP išlikimo rezultatai yra blogesni $(98,4$ proc.) nei per 60 metų $(99,1$ proc.) $(\mathrm{p}=0,058)(6$ pav. $)$.

\section{Diskusija}

Vertindami pacientų po kelio sąnario endoprotezavimo operacijų rezultatus, nustateme, jog bendras kelio sąnarių implantų išlikimas sieke 98,9 proc. praejjus vidutiniškai 30 mènesių po pirminès operacijos. Bendras kelio sąnario EP išlikimas, aprašytas Švedijos kelio sąnario endoprotezavimo registro ataskaitoje tokiu pačiu sekimo laikotarpiu, siekia 97-98 proc., Danijos ir Norvegijos registro ataskai-

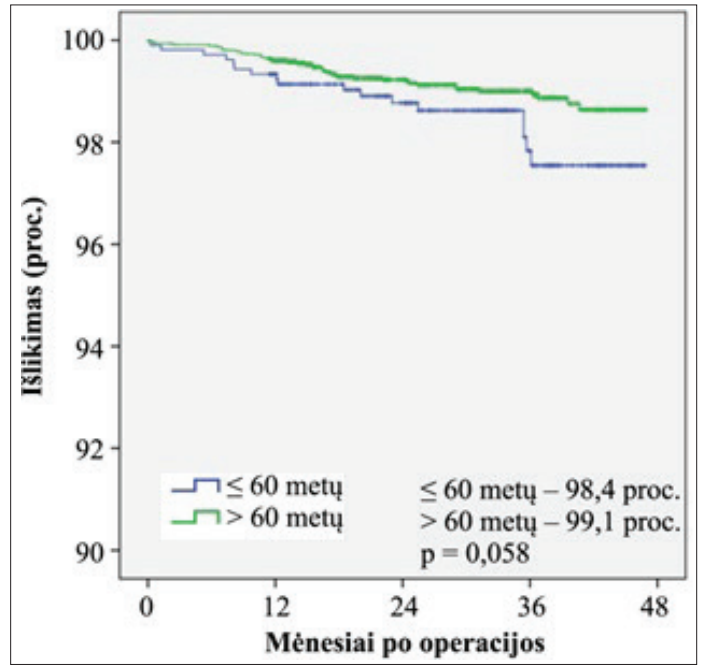

6 pav. Kelio sąnario EP išlikimo palyginimas tarp dviejų amžiaus grupių pacientų 
toje - 96-97 proc. $(12,13)$. Lyginant Lietuvos ir kitų, ypač Skandinavijos šalių, kelio sąnario EP išlikimo registrų duomenis kyla tam tikrų abejonių dèl pakartotinių operacijų dažnio trumpuoju sekimo laikotarpiu. Tačiau tai nebuvo šio tyrimo tikslas vertinti priežastis, veikiančias šiuos skirtumus. Ateityje planuojame pažvelgti ị šią problemą giliau.

Mūsų tyrime palyginus kelio sąnario implantų išlikimą tarp dviejų amžiaus grupių stebėta, kad jaunesnių pacientų amžiaus grupèje EP išlikimo rezultatai yra blogesni, taip pat stebèti šiek tiek geresni vyriškosios lyties pacientų implantų išlikimo rezultatai. Nors skirtumai nèra statistiškai reikšmingi, tačiau, kitų šalių tyrimu duomenimis, ši tendencija yra labai panaši $(4,13)$.

Vertindami operacinių pjūvių įtaką išlikimo rezultatams, stebejome mažesni, nors statistiškai ir nereikšmingą, kelio sąnario endoprotezų išlikimą operacijos metu naudojant subvastus pjūvị, lyginant su kitais kelio sąnario operaciniais pjūviais. Tai galima paaiškinti tuo, kad naudojant ši pjūvị dažniausiai atliekamos minimalios invazijos kelio sąnario endoprotezavimo operacijos $(14,15)$. Minimaliai invazyvi kelio sąnario operaciné technika yra susijusi su greitesniu paciento funkciju pagerèjimu ir mažesniu pooperaciniu skausmu $(16,17)$, tačiau ir didesniu operacinių klaidų skaičiumi dèl riboto operacinio lauko matomumo. Literatūroje pateikiama duomenų, kad ši technika gali būti susijusi su didesne neteisingos komponentu padèties implantacijos rizika (14), kas ir galèjo lemti mūsų pastebètą trumpesni EP išlikimą pacientams, operuotiems atliekant subvastus pjūvị. Šiandien dar neatsakyta ị klausimą, kas svarbiau pacietui - greitesnis pooperacinis funkcijos pagerèjimas ar ilgalaikis EP išlikimas.

\section{Išvados}

1. Pacientams Lietuvoje, kuriems atliekamos kelio sąnario endoprotezavimo operacijos, jaunesnių pacientų amžiaus grupejje EP išlikimo rezultatai yra blogesni bei šiek tiek geresni vyriškosios lyties pacientų implantų išlikimo rezultatai.

2. Subvastus pjūvis, lyginant su naudojamais kitais chirurginiais pjūviais, pacientams, kuriems atliekamos kelio sąnario endoprotezavimo operacijos, lemia didesnę pakartotinès operacijos riziką.

\section{Literatūra}

1. Ethgen O, Bruyere O, Richy F, Dardennes C, Reginster JY. Health-related quality of life in total hip and total knee arthroplasty. A qualitative and systematic review of the literature. The Journal of bone and joint surgery American volume 2004;86$\mathrm{a}(5): 963-74$.

2. Older J. Charnley low-friction arthroplasty: a worldwide retros- pective review at 15 to 20 years. The Journal of arthroplasty 2002;17(6):675-80.

https://doi.org/10.1054/arth.2002.31973

3. Tarasevicius S, Cebatorius A, Valaviciene R, Stucinskas J, Leonas L, Robertsson O. First outcome results after total knee and hip replacement from the Lithuanian arthroplasty register. Medicina (Kaunas, Lithuania). 2014;50(2):87-91.

https://doi.org/10.1016/j.medici.2014.06.004

4. Swedish Knee Arthroplasty Register. Annual Report 2008, 2009.

5. Enocson A, Hedbeck CJ, Tidermark J, Pettersson H, Ponzer S, Lapidus LJ. Dislocation of total hip replacement in patients with fractures of the femoral neck. Acta orthopaedica 2009;80(2):184-9.

https://doi.org/10.3109/17453670902930024

6. von Knoch F, Marchie A, Malchau H. Total joint registries: a foundation for evidence-based arthroplasty. The virtual mentor : VM. 2010;12(2):124-9.

https:/doi.org/10.1001/virtualmentor.2010.12.2.oped1-1002

7. Herberts $P$, Malchau H. Long-term registration has improved the quality of hip replacement: a review of the Swedish THR Register comparing 160,000 cases. Acta orthopaedica Scandinavica 2000;71(2):111-21.

https://doi.org/10.1080/000164700317413067

8. Registras LSE. Klubo sąnario operacijos registracijos forma 2015 [cited 201511 13]. Available from: https://registras.lsed. lt/index.php/klubo_irasas/new.

9. Registras LSE. Kelio sąnario operacijos registracijos forma 2015 [cited 201511 13]. Available from: https://registras.lsed. 1t/index.php/kelio_irasas/new.

10. Kolling C, Simmen BR, Labek G, Goldhahn J. Key factors for a successful National Arthroplasty Register. The Journal of bone and joint surgery British volume 2007;89(12):1567-73. https://doi.org/10.1302/0301-620X.89B12.19409

11. Li T, Zhuang Q, Xiao K, Zhou L, Weng X. Comparison of the clinical and radiological outcomes following midvastus and medial parapatellar approaches for total knee arthroplasty: a meta-analysis. Chinese medical journal 2014;127(16):2982-90.

12. Robertsson O, Bizjajeva S, Fenstad AM, Furnes O, Lidgren L, Mehnert F. et al. Knee arthroplasty in Denmark, Norway and Sweden. A pilot study from the Nordic Arthroplasty Register Association. Acta orthopaedica 2010;81(1):82-9. https://doi.org/10.3109/17453671003685442

13. Swedish Knee Arthroplasty Register. Annual Report 2009. Report. 2010 2010. Report No.

14. Costa CR, Johnson AJ, Harwin SF, Mont MA, Bonutti PM. Critical review of minimally invasive approaches in knee arthroplasty. The journal of knee surgery 2013;26(1):41-50. https://doi.org/10.1055/s-0032-1313751

15. Bonutti PM, Zywiel MG, McGrath MS, Mont MA. Surgical techniques for minimally invasive exposures for total knee arthroplasty. Instructional course lectures 2010;59:83-91. 
16. Halder A, Beier A, Neumann W. [Mini-subvastus approach for total knee replacement]. Operative Orthopeadie und Traumatologie 2009;21(1):14-24. https://doi.org/10.1007/s00064-009-1602-1

17. Teng Y, Du W, Jiang J, Gao X, Pan S, Wang J, et al. Subvastus versus medial parapatellar approach in total knee arthroplasty: meta-analysis. Orthopeadics 2012;35(12):e1722-31.

https://doi.org/10.3928/01477447-20121120-16

\section{PATIENT GENDER, AGE AND APPROACH IMPACT ON REVISION RATE AFTER A TOTAL KNEE REPLACEMENT SURGERY}

\section{A. Čebatorius, A. Lebedev, J. Stučinskas, S. Laukaitis,}

\section{Senkanec}

Key words: total knee arthroplasty, osteoarthritis, operating approach, revisional surgery, Lithuanian arthroplasty registry, implant survival rate.

\section{Summary}

Total knee arthroplasty procedure is one of the most commonly performed orthopeadic procedures in Lithuania. A number of factors have a certain influence on treatment results. The aim of this study was to assess patient's sex, age, and operating approach affect on revision surgery rate for patients undergoing a total knee replacement. The study included all Lithuanian arthroplasty registry database records of primary knee arthroplasty cases since January 1st of 2011 to the December 31st of 2013 and further follow up untill December 31st of 2014. All the revision cases were also recorded. The main evaluation criteria was implant survival rate after the initial surgery. According to the survey, during the period of 2011-2013 there were 4436 knee arthroplasties performed for women and 1119 for men. The medial parapatelar approach was used in majority of cases (88\%). There were 59 revisions registered during the same period that represents a total of $1.1 \%$. Knee implant survival rate was $98.9 \%$ after an average of 30 months. A slightly better results after arthroplasty were observed for male patients $(99.0 \%)$, comparing to female patients $(98.9 \%)$, however the difference was not statisticaly significant. Comparing knee implant survival rate between two age groups the worse implant survival rate was found in patients younger than 60 years age group (98.4\%), comparing to $99.1 \%$ in patients older than 60 years of age. Correspondence to: a.cebatorius@gmail.com

Gauta 2017-01-05 